CASE STUDY

\title{
Total Diet Study approach in estimating mercury and cadmium levels using selected fish: A case study from Sri Lanka
}

\author{
G.D.T.M. Jayasinghe1 ${ }^{1}$ K.P.G.L. Sandaruwan ${ }^{2}$, D.W.L.U. Silva² and B.K.K.K. Jinadasa ${ }^{1, *}$
}

\author{
${ }^{1}$ Analytical Chemistry Laboratory (ACL), National Aquatic Resources Research \& Development Agency (NARA), \\ Colombo 15, Sri Lanka \\ ${ }^{2}$ Socio-Economic \& Marketing Division, National Aquatic Resources Research \& Development Agency (NARA), \\ Colombo 15, Sri Lanka
}

Received:14/12/2017; Accepted:11/05/2018

\begin{abstract}
Total Diet Study (TDS) is a world-recognized approach in quantifying nutrients and contaminants in complete diets. In the present study, the TDS approach was used to determine the dietary exposure to mercury $(\mathrm{Hg})$ and cadmium $(\mathrm{Cd})$ by regular consumption of yellowfin tuna (YFT), swordfish (SWF) and sardinella (SAF) fish in Gampaha district, Sri Lanka. The study was based on the TDS method established by the World Health Organization (WHO). $\mathrm{Hg}$ and $\mathrm{Cd}$ were analyzed using Atomic Absorption Spectrophotometer after microwave digestion of samples. Survey results revealed that the weekly average fresh fish consumption was $301 \mathrm{~g}$ per person. $\mathrm{Hg}$ and $\mathrm{Cd}$ levels were calculated on the wet weight basis. The maximum allowable limits of $\mathrm{Hg}$ and $\mathrm{Cd}$ were compared with European Union/European Commission (EU/EC) regulation limits for each species. None of the samples exceeded the EU/EC maximum limit for $\mathrm{Cd}$, but two samples of SWF exceeded the maximum limit for $\mathrm{Hg}$, recommended by the EU/EC. The Provisional Tolerable Weekly Intake (PTWI) for $\mathrm{Hg}$ was calculated for risk assessment. The percentage contributions of SWF, YFT, and SAF for PTWI-Hg were 64.92 and 40.16 and 8.55 respectively. Accordingly, the SWF were close to exceed the PTWI value. YFT and SWF are considered as the top predators in the marine food web. Cooking did not significantly reduce the $\mathrm{Hg}$ and $\mathrm{Cd}$ contents in selected fish species. Further studies are recommended to evaluate the PTWI values for predatory fish species before consumption.
\end{abstract}

Keywords: Provisional Tolerable Weekly Intake (PTWI), Mercury, Cadmium, Risk, Seafood.

\section{INTRODUCTION}

Seafood refers to food including mainly fish, crustaceans, mollusks, and seaweeds derived from aquatic resources originating from marine and brackish water environments. Seafood provides a variety of nutrients thus beneficial in making healthy diets. Dietary guidelines state that the increase in consumption of fish and fishery products contain health benefits (Morales and Higuchi, 2018). The per capita fish consumption of a Sri Lankan is $15.3 \mathrm{~kg}$ / year, but according to Ministry of Health (2016) it should be increased up to $21 \mathrm{~kg} /$ year (Ministry of Health, 2016).
As larger fish species are in higher positions of food webs compared to smaller fish species, hazardous substance accumulation of the former might be 1,000 times higher than that of the latter (Johnson and Finley, 1980). Hazardous substances such as persistent organic pollutants (POP's), Polychlorinated biphenyl (PCB's), dioxins, furans and other environmental contaminates like mercury $(\mathrm{Hg})$, cadmium $(\mathrm{Cd})$ and lead $(\mathrm{Pb})$ are accumulated in fish and eventually transfer to humans through consumption (Jinadasa et al., 2016).

Mercury is a naturally occurring non-essential trace metal that exists in several forms such as metallic, organic and inorganic in the environment including water, air, and soil (Jinadasa et al., 2015). Organic Hg, especially in the form of methylmercury ( $\mathrm{MeHg}$ ) is mainly found in seafood and it forms an extremely stable complex with sulfhydryl groups (Schmidt et al., 2018). As Methyl Hg is the most toxic form it attracts more attention globally (Jinadasa et al., 2015). Previous studies demonstrate that $\mathrm{Hg}$ contaminants can't be removed through trimming, cooking and skinning because $\mathrm{MeHg}$ binds to protein in muscle tissues of fish. Urine and the feces are the most common excretory pathways of inorganic $\mathrm{Hg}$ (Berger et al., 2003) $\{\mathrm{B}, 2003$ \#21;Berger, 2003 \#285\}. The accumulation of $\mathrm{Hg}$ especially $\mathrm{MeHg}$ in humans may damage the central nervous system, especially in the fetal and early growth stages. European Union/European Commission (EU/EC) and Government of Sri Lanka regulations (EU/EC-1881, 2006; GOSL, 1528/7) indicate safety levels for Total Hg (T$\mathrm{Hg}$ ) in fish and fishery products. According to those safety regulations, the maximum $\mathrm{Hg}$ level in wet weight basis is 1 $\mathrm{mg} / \mathrm{kg}$ for yellowfin tuna (YFT) and swardfish (SWF) and $0.5 \mathrm{mg} / \mathrm{kg}$ for sardinella (SAF). Based on the exposure risk assessment, Food and Agricultural Organization (FAO) and World Health Organization (WHO) Joint Expert Committee on Food Additives (JECFA) published the provisional tolerable weekly intake (PTWI) values (Popovic et al., 2018). Food and Drug Administration of the United States of America (US-FDA) and EU also advise avoiding the consumption of fish which contain T-Hg higher than $1 \mathrm{mg} /$

*Corresponding Author's Email: jinadasa76@gmail.com http://orcid.org/0000-0002-4232-6338 
kg (USFDA, 1994).

Cadmium $(\mathrm{Cd})$ is a metal that can become toxic to all life forms including humans even at low concentrations. Cadmium is associated with cancer, birth defects and genetic mutations (Lundh et al., 2016). Cadmium is released into the environment by industrial (coal power plant, mining etc.) or domestic effluents (electronic waste) or through natural activities (volcanic eruptions). Fish can accumulate $\mathrm{Cd}$ through contaminated food chains, finally exposing to humans who regularly consume shellfish and fish organs such as liver and kidney. As YFT and SWF are on the upper level of the food web, the bio-accumulation of contaminants including $\mathrm{T}-\mathrm{Hg}$ is higher than in small pelagic fish species (Jinadasa et al., 2014).

In Sri Lanka, different cooking methods are used to prepare fish and fishery products. The main cooking methods are milk/chilli curry, roasting and frying. Several researchers have evaluated $\mathrm{Hg}$ in different food types, but not much information is available on cooked fish. Mieiro et al (2016) demonstrated that high-temperatures in cooking fish may reduce the volatile character of $\mathrm{MeHg}$. Most countries practice the Total Diet Study (TDS) approach to quantify the nutrients and contaminants in complete diets. It is an universal approach to estimate and monitor dietary exposures to chemical substances such as additives, residues of phytosanitary products or veterinary medications, environmental contaminants, natural toxins, nutrients and micronutrient (USFDA, 2014). The TDS approach is mainly based on the food consumption data collected from a sample of a population (more than $1 \%$ of the total population). Development of the food list, food sampling and kitchen preparation of samples are also based on in the TDS survey. The main objective of the present study was to establish a methodology for TDS relevant to Sri Lanka and to analyze $\mathrm{T}-\mathrm{Hg}$ and Cd contents in cooked samples of YFT, SWF and SAF.

\section{MATERIALS AND METHODS}

The methodology for TDS was established based on the WHO guidelines and previous TDS studies carried out in France, Tanzania, and Italy (Peltonen et al., 2011, Gimou et al., 2008). Food consumption data were collected from the Gampaha district which represents both urban and rural populations, during the period from January to August 2016 using a questionnaire (Sandaruwan et al., 2017). Data were obtained through two non-consecutive 24-hour dietary questionnaires taken from 152 families. Negombo fish landing site and other popular fish markets (Peliyagoda and Chilaw) are located close by Gampaha district. The samples were analyzed from September to December 2016.

\section{Sample collection}

List of fish species was prepared using food consumption data. The individual approach was followed to analyze the trace metals, T-Hg and Cd. YFT and SWF are the most abundant larger pelagic species and SAF is the most abundant small pelagic fish species consumed by the people in the Gampaha district. YFT, SWF, and SAF samples were collected from mobile fish vendors as well as from the Ceylon Fishery Corporation (CFC) fish stall, Peliyagoda fish market and super markets. The collected samples (11 samples each weighing $500 \mathrm{~g}$ ) were immediately transported in insulated boxes containing ice to the laboratory at NARA.

\section{Sample preparation and culinary process}

Details of cooking methods, ingredients (varieties and quantity), containers, and energy sources were collected from the TDS survey. Accordingly, YFT, SWF, and SAF were prepared using the cooking methods obtained from the TDS survey. The T-Hg and Cd contents of cooked fish samples were analyzed. YFT and SWF fillets were taken (devoid of skin and bone) while SAF were cleaned by removing the gut, gills, and scales before cooking. The fish samples were cooked according to the culinary methods used by the local people using the same spices and other ingredients. The fish samples were prepared as a milk curry, chili curry and 'ambulthial' at the ratio of 6:3:2, and the cooking times were 15, 20 and 25 minutes in the ratio of 5:5:1. The energy sources used were gas: fire wood at the ratio of 5:6. Clay pots and aluminum containers were used in the ratio of $9: 2$.

\section{Total mercury (T-Hg) and cadmium analysis}

The chemicals used in the analyses were of the analytical grade. Standard solutions of the metals $(1,000 \mathrm{mg} / \mathrm{L})$ were obtained from Fluka, Switzerland. The glassware was soaked overnight in a liquid detergent solution and thoroughly rinsed with tap water, before soaking them in $10 \%(\mathrm{v} / \mathrm{v}) \mathrm{HNO}_{3}$ overnight and rinsed in de-ionized water and oven dried before using. The plastic ware was air dried prior to use.

One gram of homogenized sample was weighed in a microwave digester tube and $10 \mathrm{~mL}$ of concentrated nitric acid (65\%, AR-Sigma) was added and kept for 15 minutes in a fume hood for pre-digestion. After pre-digestion, the samples were digested using a microwave accelerated system (CEM-Mars-6). Each sample was analyzed in duplicate. Two blank tubes prepared in a similar manner (but without the muscle) were included in each batch of analysis. Microwave conditions were set at 800 PSI pressure, $200{ }^{\circ} \mathrm{C}$ temperature with a $10 \mathrm{~min}$ holding time.

The digests were allowed to cool to room temperature and the pressure was released carefully by opening the valve. Each digested fish sample was transferred into 50 $\mathrm{mL}$ volumetric flask and was diluted up to the mark with deionized water. The determination of T-Hg was performed using a Cold Vapor Atomic Absorption Spectrometry system (CV-AAS: Varian VGA 77) in a Varian 240 FS atomic absorption spectrophotometer (Varian 240 FS, Varian Inc., Mulgrave, Victoria, Australia) using $\mathrm{SnCl}_{2}$ as a reduction solution throughout the analysis. The $\mathrm{Cd}$ was analyzed using a graphite tube atomizer (Varian GTA 120). A calibration curve for $\mathrm{T}-\mathrm{Hg}(5-50 \mu \mathrm{g} / \mathrm{L})$ and $\mathrm{Cd}(0.5-3.0$ $\mu \mathrm{g} / \mathrm{L})$ were obtained. Using the standard curve, readings were obtained for blanks, samples and quality control sample (QC). 


\section{Quality control procedure}

The accuracy of the analytical procedure was maintained throughout the analysis using certified quality control material (canned fish muscle, T/07194) from Food Analysis Performance Assessment Scheme (FAPAS, Sand Hutton, York, UK) for $\mathrm{T}-\mathrm{Hg}$ and $\mathrm{Cd}$. The average field blank, derived from sample field blanks, and three times its standard deviation were used to evaluate the limit of detection (LOD). The limit of quantification (LOQ) was 3 $\times$ LOD. The descriptive analyses were done using SPSS software version 17.0.

\section{RESULTS AND DISCUSSION}

This study provides information about $\mathrm{T}-\mathrm{Hg}$ and $\mathrm{Cd}$ contents in cooked YFT, SWF and SAF species. The suitability of this method was evaluated by calculating the Limit of Quantification (LOQ) and the recovery of certified quality control measures for $\mathrm{T}-\mathrm{Hg}$ and $\mathrm{Cd}$. The LOQ for $\mathrm{T}-\mathrm{Hg}$ and $\mathrm{Cd}$ was 0.07 and $0.006 \mathrm{mg} / \mathrm{kg}$ respectively. The assigned recovery value of quality control of samples $(\mathrm{n}=$ 10) for $\mathrm{Hg}(\mathrm{T}-7194 \mathrm{QC})$ was $141 \mu \mathrm{g} / \mathrm{kg}$ and the recovery was $106.7 \%( \pm 7.90)$ and the assigned value for $\mathrm{Cd}$ for the same QC sample was $4.99 \mu \mathrm{g} / \mathrm{kg}$ and the recovery was $95.10 \%( \pm 13.34)$. The expanded uncertainty $(\mathrm{k}=2)$ of $\mathrm{Hg}$ and $\mathrm{Cd}$ was 9.0 and $8.8 \%$, respectively. The results indicate the validity of this method for determining the $\mathrm{T}-\mathrm{Hg}$ and $\mathrm{Cd}$ concentrations in the samples investigated.

The food consumption data were collected from a population-based food consumption survey conducted in the Gampaha District in 2016 (Sandaruan et al, 2017). Data were obtained through two non-consecutive 24-hour dietary questionnaires taken from 152 families. Based on the survey, weekly average fish consumption was 301 g per person. Eleven common fish species namely IndoPacific sailfish, shark, mackerel, yellowfin tuna, skipjack tuna, seer fish, trevally, spotted sardinella, sardinella, anchovy and mullets were identified. However, the individual approaches were practiced on the first three species ranked in the survey. The $\mathrm{T}-\mathrm{Hg}$ and $\mathrm{Cd}$ contents of cooked fish samples were shown in table 1 (given on wet basis).

According to the EU regulation (EU/EC 1881/2006 GOSL 1528/7) for T-Hg, the maximum allowable level was $1 \mathrm{mg} / \mathrm{kg}$ for SWF and YFT, while $0.5 \mathrm{mg} / \mathrm{kg}$ for SAF in wet weight basis. However, the EU/EC 488/2014, the maximum level of Cd was $0.1 \mathrm{mg} / \mathrm{kg}$ for YFT while 0.25 $\mathrm{mg} / \mathrm{kg}$ for SWF and SAF. Sample numbers 6 (chili curry cooked for 15 minutes) and 7 (milk curry, 25 minutes) of SWF exceeded the maximum allowable level recommended by EU and GOSL. The YFT and SWF are considered as the top predators in the marine food chain and commercially important fish species in the Sri Lankan fish market. The results of the present study also suggest that the $\mathrm{T}-\mathrm{Hg}$ content in the fish muscle is comparatively higher in larger fish species than in small pelagic fish species such as SAF. However, none of the samples exceeded the EU maximum allowable limits for $\mathrm{Cd}$.

Chemical constituents in fish may also vary between individuals, due to age, gender, the habitat of the fish and also sampling site (Vollenweider et al., 2011). SWF and YFT are carnivorous species present in the upper part of the food web compared to that of YFT. SWF feed on fish, while YFT feeds on fish, crustaceans, and squids. Crustaceans and squids are in the lower part of the food web, and they also feed on zooplankton. The SAF mainly feed on phytoplankton and zooplankton (Gushchin and Corten, 2015). As a result, the bio-accumulation and biomagnification of $\mathrm{T}-\mathrm{Hg}$ is reduced in large fish than in small fish. This is perhaps the reason that the highest $\mathrm{T}-\mathrm{Hg}$ content recorded in SWF than in YFT.

\section{Risk assessment of fresh and cooked fish}

The exposure for $\mathrm{Hg}$ was estimated and calculated using the consumption data received from the TDS survey. The

Table 1: T-Hg and Cd contents $(\mathrm{mg} / \mathrm{kg}$ ) in cooked fish samples of SWF (swordfish), YFT (yellowfin tuna) and SAF (sardinella).

\begin{tabular}{lcccccc}
\hline Fish No & $\mathbf{H g}, \mathbf{m g} / \mathbf{k g}$ & \multicolumn{5}{c}{$\mathbf{C d}, \mathbf{m g} / \mathbf{k g}$} \\
\hline & SWF & YFT & SAF & SWF & YFT & SAF \\
\hline 1 & 0.16 & 0.11 & "ND & ND & 0.007 & 0.021 \\
2 & 0.45 & 0.25 & ND & 0.006 & 0.012 & 0.019 \\
3 & 0.06 & 0.27 & 0.07 & ND & 0.012 & 0.016 \\
4 & ND & 0.51 & ND & 0.006 & 0.049 & 0.014 \\
5 & 0.44 & ND & ND & 0.027 & 0.015 & 0.014 \\
6 & 1.47 & ND & 0.07 & 0.029 & 0.015 & 0.007 \\
7 & 1.07 & 0.11 & 0.07 & 0.014 & 0.010 & 0.014 \\
8 & 0.42 & 0.95 & 0.09 & ND & 0.021 & 0.014 \\
9 & 0.19 & 0.44 & 0.07 & ND & 0.007 & 0.016 \\
10 & 0.11 & 0.19 & ND & ND & 0.009 & 0.016 \\
11 & 0.34 & ND & 0.08 & 0.021 & 0.016 & 0.021 \\
\hline
\end{tabular}

\#ND-Not Detected 
PTWI values for $\mathrm{Hg}$ and $\mathrm{Cd}$ are $4 \mu \mathrm{g} / \mathrm{kg}$ and $7 \mu \mathrm{g} / \mathrm{kg}$ of body weight, respectively. However, the European Food Safety Authority has given the Tolerable Weekly Intake (TWI) value of $2.5 \mu \mathrm{g} / \mathrm{kg}$ bodyweight for $\mathrm{Cd}$. The PTWI value was calculated assuming that an average body weight of a person is $50 \mathrm{~kg}$. Accordingly, the PTWI values for an average person were $200 \mu \mathrm{g}$ for $\mathrm{T}-\mathrm{Hg}$ and $350 \mu \mathrm{g}$ for $\mathrm{Cd}$ (Subasinghe et al., 2012).

Weekly average fresh fish consumption per person was 301 g. Percentage contributions of SWF, YFT, and SAF for PTWI-Hg were 64.9, 40.2 and 8.6, respectively. The results suggest that SWF species was closer to exceed the PTWI value, indicating that an average person $(50 \mathrm{~kg}$ body weight) should not eat more than $425 \mathrm{~g}$ of SWF per week. The EU \& USFDA regulations have clearly mentioned that children, pregnant women, lactating women, and women who are planning to get pregnant should refrain from eating SWF and YFT. The study confirmed that the contribution of SWF and SAF for PTWI-Cd was negligible, but YFT recorded $2.37 \%$ for PTWI-Cd. The study recommends further studies to find out the efficiency levels of different cooking method to reduce $\mathrm{T}-\mathrm{Hg}$ in fish.

\section{CONCLUSION}

The percentage contribution of SWF, YFT \& SAF species for $\mathrm{Hg}$, PTWI was 75.4, 40.5 and 7.6, respectively. As SWF was closer to exceed the PTWI value, people should be advised not to consume SWF more than $425 \mathrm{~g}$ per week. However, the levels of $\mathrm{Cd}$ in studied fish species were significantly lower than established PTWI values.

\section{REFERENCES}

Berger, J., Dixon, C. \& Boring, C. S. (2003). Effect of deep-frying fish on risk from mercury. Journal of Toxic Environ Health, Part A., 66: 817-828.

Disanayaka, D. T. C., Samaraweera E.K.V. \& Amarasiri, C. (2008). Fisheries and Feeding habits of yellowfin tuna (Thunnus albacares) targeted by coastal tuna long lining in the north western and north eastern coasts of Sri Lanka. Sri Lanka Journal of Aquatic Science. 13: $1-21$.

EU/EC-1881 (2006). Commission Regulation (EC), No 1881/06 of setting maximum levels for certain contaminants in food stuff. Official Journal of European Union L364: 5-24.

FB, 2017. www.fishbase.org, accessed date, 01st May 2017.

Gimou, M.M., Charrondiere, U.R., Leblanc, J.C. and Pouillot, R. (2008). Dietary exposure to pesticide residues in Yaoundé: The Cameroonian total diet study. Food Additives \& Contaminants: Part A 25(4): 458-471

Gushchin, A. V.and Corten, A. 2015. Feeding of pelagic fish in waters of Mauritania: 1. European anchovy Engraulis encrasicolus, European sardine Sardina pilchardus, round sardinella Sardinella aurita, and flat sardinella S. maderensis. Journal of Ichthyology, 55: 77-85.

Jinadasa, B. K. K. K., Edirisinghe, E. M. R. K. B. and Wickramasinghe, I. (2014). Total mercury, cadmium and lead levels in main export fish of Sri Lanka. Food Additives \& Contaminants: Part B 7(4): 309-314

Jinadasa, B. K. K. K., Mahaliyana, A. S., Liyanage, N. P. P. \& Jayasinghe, G. D. T. M. (2015). Trace metals in the muscle tissues of the skipjack tuna (Katsuwonus pelamis) in Sri Lanka Cogent Food and Agriculture 171: $1-10$.

Jinadasa, B. K. K. K., Zoysa, H. K. S. D., Jayasinghe, G. D. T. M. \& Edirisinghe, E. M. R. K. B. (2016). Determination of the Biometrical parameters, Biochemical composition and essential trace metals of edible sea urchin (Stomopneustes variolaris) in Sri Lanka Cogent Food and Agriculture 4: 1-7.

Johnson, W. W. and Finley, M. T. (1980). Handbook of Acute Toxicity of Chemicals to Fish and Aquatic Invertebrates 37: 12-14.

Lundh, T., Axmon, A., Skerfving, S. and Broberg, K. (2016). Cadmium and mercury exposure over time in Swedish children. Environmental Research 150: 600605.

Mieiro, C. L., Coelho, J. P., Dolbeth, M., Pacheco, M., Duarte, A. C., Pardal, M. A. and Pereira, M. E. (2016). Fish and mercury: Influence of fish fillet culinary practices on human risk. Food Control 60: 575-581.

Mendez, E., Giudice, H., Pereira, A., Inocente, G. and Medina, D. 2001. Total Mercury Content Fish Weight Relationship in Swordfish (Xiphias gladius) Caught in the Southwest Atlantic Ocean. Journal of Food Composition and Analysis 14: 453- 460.

Health Economics Cell (2016). Sri Lanka National Health Account 2013, Colombo, Sri Lanka Ministry of Health, Nutrition \& Indigenous Medicine SEMD 2015. Fisheries Industry Outlook 2015. Colombo, Sri Lanka.

MOFAR (2016). Fisheries statistics. Colombo: Ministry of Fisheries and Aquatic Resources, Colombo, Sri Lanka.

Morales, L. E. and Higuchi, A. (2018). Is fish worth more than meat? - How consumers' beliefs about health and nutrition affect their willingness to pay more for fish than meat. Food Quality and Preference 65: 101-109.

Peltonen, K., Charrondiere, R., Georgescu, I. M., Kambek, L., Lombardi-Boccia, G., Lindtner, O., Marcos Suarez, V., Oliveira, L., Ruprich, J. \& Shavila, J. (2011). Towards a Harmonised Total Diet Study Approach: a guidance document: joint guidance of EFSA, FAO and WHO. World Health Organization.

Popovic, A. R., Djinovic-Stojanovic, J. M., Djordjevic, D. S., Relic, D. J., Vranic, D. V., Milijasevic, M. P. \& Pezo, L. L. 2018. Levels of toxic elements in canned fish from the Serbian markets and their health risks assessment. Journal of Food Composition and Analysis 67: 70-76.

Schmidt, L., Figueroa, J. A. L., Dalla Vecchia, P., Duarte, F. A., Mello, P. A., Caruso, J. A. \& Flores, E. M. M. (2018). Bioavailability of $\mathrm{Hg}$ and Se from seafood after culinary treatments. Microchemical Journal 139: 363371.

Sandaruwan, K. P. G. L, Silva D. W. L. U., Jayasinghe G. D. T. M. \& Jinadasa B. K. K. K. 2017. Consumption behaviour in Gampaha district, Sri Lanka socioeconomic determinants of the fish purchasing decision and consumption behavior in Gampaha district, Sri Lanka. NARA annual scientific session, 27th July 2017, 
Colombo, Sri Lanka.

Subasinghe M. M., Jinadasa, B. K. K. K. \& Wickramasinghe, I., 2012. Accumulation of toxic and essential trace metals in four fish species from Anuradhapura district, Sri Lanka. First national symposium of the potential health, environmental impact of exposure to hazardous natural and man-made chemical and their proper management. 23rd Nov. 2012, Colombo, Sri Lanka, Pp2-8.

USFDA. 1994. "US Food and Drug Administration". In Mercury in fish: Cause of concern?, FDA Consumer Magazine.

Vandermeersch, G., Lourenço, H. M., Alvarez-Muñoz, D., Cunha, S., Diogène, J., Cano-Sancho, G., Sloth, J. J., Kwadijk, C., Barcelo, D., Allegaert, W., Bekaert, K., Fernandes, J. O., Marques, A. and Robbens, J. (2015). Environmental contaminants of emerging concern in seafood - European database on contaminant levels. Environmental Research 143: 29-45.

Vollenweider, J. J., Heintz, R. A., Schaufler, L.and Bradshaw, R. 2011. Seasonal cycles in whole-body proximate composition and energy content of forage fish vary with water depth. Marine biology, 158: 413427. 